\title{
Expression of Adhesion Molecules during Tooth Resorption in Feline Teeth: A Model System for Aggressive Osteoclastic Activity
}

\author{
Y. Shigeyama ${ }^{1}$, T.K. Grove ${ }^{3}$, C. Strayhorn ${ }^{1}$, and M.J. Somerman ${ }^{1,2^{*}}$
}

Departments of ${ }^{1}$ Periodontics/Prevention/Geriatrics and ${ }^{2}$ Pharmacology, School of Medicine, University of Michigan, 1011 N. Universify, Ann Arbor, Michigan 48109-1078; ${ }^{3}$ The Florida Veterinary Dental Clinic, 87517 th Street, Vero Beach, Florida 32960 ; ${ }^{*}$ to whom correspondence should be addressed

\begin{abstract}
Tooth resorption, a common feline dental problem, is often initiated at the cemento-enamel junction and hence is called cat 'neck' lesion. Studies have demonstrated that osteoclasts/odontoclasts are increased and activated at resorption sites, and that areas of resorption are partly repaired by formation of tissues resembling bone, cementum, and possibly dentin. However, the cellular/molecular mechanisms/factors involved in resorption and repair are unknown. In this study of tissues from cats with 'neck' lesions, we used specific antibodies and immunohistochemical analyses to examine adhesion molecules associated with mineralized tissues, bone sialoprotein (BSP) and osteopontin (OPN), and a cell-surface receptor linked with these molecules, $\alpha_{v} \beta_{3}$, for their localization in these lesions. In addition, to determine general cellular activity during repair, we performed in situ hybridization using a type I collagen riboprobe.

Results showed OPN localized to resorption fronts and reversal lines, while BSP was localized to reversal lines. However, some osteoclasts and odontoblasts "sat" on mineralized surfaces not associated with OPN. The cellsurface receptor, $\alpha_{v} \beta_{3}$, was localized to surfaces of osteoclasts/odontoclasts. Type I collagen mRNA was expressed where osteoblasts attempted to repair mineralized tissue. In contrast, odontoblasts did not express mRNA for type I collagen. This study suggests that osteoclastic resorption is the predominant activity in 'neck' lesions and that this activity was accompanied, at least in part, by increased concentrations of OPN and an associated integrin, $\alpha_{\mathrm{v}} \beta_{3}$, at resorption sites. Lack of collagen expression by odontoblasts indicates that odontoblasts do not play an active role in attempts at repair.
\end{abstract}

Key words: $\alpha_{v} \beta_{3}$, bone sialoprotein, odontoclasts, osteoclasts, osteopontin.

Received May 4, 1995; Accepted February 1, 1996

\section{Introduction}

Extensive tooth resorption is common in domesticated cats (Coles, 1990). Beginning at age 4 , about $40 \%$ of cats are affected with an average of 2.3 lesions per affected cat (Harvey, 1992). Other species rarely develop this lesion (Okuda and Harvey, 1992a). The lesion is characterized by resorption beginning at the cervical region of the tooth, the cemento-enamel junction (Fig. 1). As a result, this lesion is often referred to as a 'neck' lesion or 'cervical line' lesion. With disease progression, internal resorption of tooth structures is seen. Affected cats may experience severe dental hypersensitivity, tooth fracture, tooth loss by complete subgingival resorption, a variety of aversive social behaviors, and eating disorders. Because of their clinical similarity to dental caries, these lesions were originally classified as such (Fig. 1). Early histologic studies (Schneck and Osborn, 1976) revealed osteoclast/odontoclast resorption in 'neck' lesions, and these investigators concluded that such lesions were a type of periodontal disease. A similar lesion in humans, external resorption, begins slightly apical to the cemento-enamel junction and looks, radiographically, like caries associated with xerostomia (Regezi and Sciubba, 1989). The cause of the human lesion is unknown. The lesion progresses naturally to extensive destruction and tooth loss. Although these resorptive lesions share many similarities, when the two species are compared, the rate of destruction seems much faster in cats than in humans. Additionally, in cats, the lesions occur frequently and often in multiple teeth. These characteristics as well as the accessible contained nature of the lesion make the cat a good model for the study of aggressive osteoclastic behavior.

Histologically, it has been reported that dental tissues resorbed as a consequence of disease are repaired in part by formation of mineralized tissues resembling bone, cementum, and/or dentin (osteodentin) (Reichart et al., 1984; Okuda and Harvey, 1992a). Although significant repair may occur, it rarely results in reformation of complete structural integrity. Importantly, immunohistochemical assays indicated the presence of two 

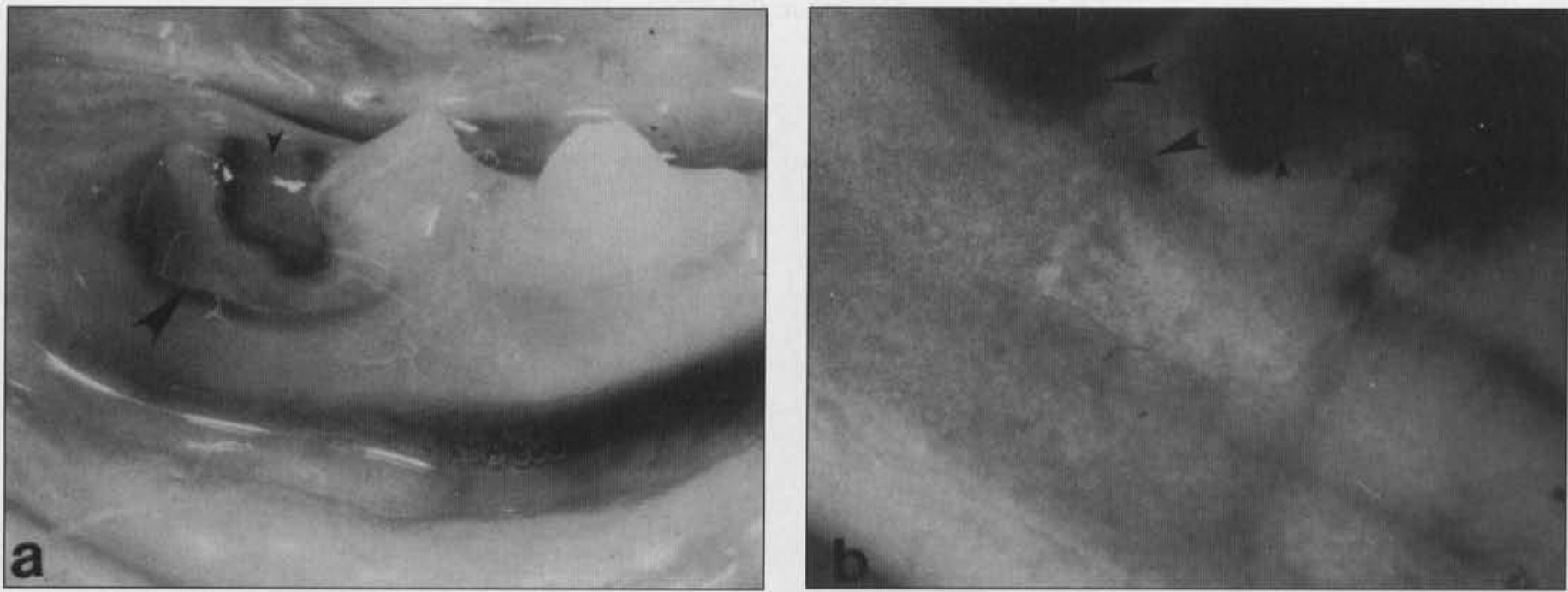

Figure 1. Photograph of cat 'neck' lesion. (a) Clinical view, lower molar. Large arrow points to cervical lesion. Note extension of the lesion into the pulp chamber, resulting in an appearance similar to that of a caries lesion (small arrow). (b) Radiograph of cat 'neck' lesion (large arrow) and caries (small arrow) in molar shown in (a).

cytokines, IL-1 and IL-6. Both of these interleukins are considered to function in recruitment and activation of osteoclasts/odontoclasts locally, prior to root resorption (Okuda and Harvey, 1992b). Also, 'odontoclastic' cells from these lesions stain positive for tartrate-resistant acid phosphatase (TRAP), an enzyme associated with osteoclasts (Okuda and Harvey, 1992b).

We hypothesized that specific adhesion molecules and their receptors play an active role in regulating root resorption and repair. Strong evidence exists that adhesion molecules direct cell behavior and differentiation during replacement of lost tissues (Albelda and Buck, 1990). We studied two adhesion molecules important in mineralized tissues, bone sialoprotein (BSP) (for review, see Fisher, 1992; Sodek et al., 1992) and osteopontin (OPN) (for review, see Denhardt and Guo, 1993; Patarca et al., 1993; Denhardt and Chambers, 1994), and an integrin linked with both BSP and OPN, $\alpha_{v} \beta_{3}$ (Reinholt et al., 1990; Helfrich et al., 1992; Ross et al., 1993). Osteopontin is a phosphorylated glycoprotein rich in sialic acid. It was originally isolated from the extracellular matrix of bone and was later identified in several other tissues and cells, including transformed cell lines and fluids. Accumulating evidence indicating that OPN modulates osteoclast function by regulating $\mathrm{Ca}^{2+}$ flux, controlling nitric oxide production and promoting osteoclast adhesion, supports a role for this adhesion molecule as a regulator of 'neck' lesions. Importantly, $\alpha_{4} \beta_{3}$ integrin is found in high concentrations on the cell surfaces of osteoclasts. OPN may also act as an inhibitor of crystal formation (Shiraga et al., 1992; Boskey et al., 1993; Hunter et al., 1994) and play a protective role by recruiting macrophages to a site of infection (Patarca et al., 1993). In contrast to OPN, the phosphorylated glycoprotein, BSP, appears to be restricted to mineralized tissues. It is most abundant in bone, cementum, and hypertrophic cartilage, but has also been identified in dentin, cartilage, and decidua. BSP could regulate mineralization (Sodek et al., 1992), possibly by functioning as a nucleator (Hunter and Goldberg, 1994). We expected that OPN and $\alpha_{v} \beta_{3}$ integrin would associate with osteoclasts present in cat 'neck' lesions and that both OPN and BSP would be found in proximal repairative tissue.

\section{Materials and methods}

\section{Tissue preparations}

Tissues selected for analysis were removed for humane reasons from 14 cats, aged from 7 to 13 years, with clinical signs of extensive lesions in the hard structure of the teeth at the gingival margin. Extractions were performed at a veterinary practice (Dr. Keith Grove, Vero Beach, FL), and the procedures were reviewed and approved by the Animal Care Committee, University of Michigan. With the cats under general anesthesia, diseased teeth and surrounding tissues were removed with a high-speed carbide bur. Samples were immediately placed in Bouin's fixative $(0.9 \%$ picric acid, $9 \% \mathrm{v} / \mathrm{v}$ formaldehyde, $5 \%$ acetic acid; Polysciences, Warrington, PA) and kept there overnight. The use of Bouin's fixative and other procedures described were based on our previous studies indicating that mouse and monkey tissues maintain both antigenicity and molecular integrity for OPN and BSP with this fixative (MacNeil et al., 1994, and personal communication). Next, samples were demineralized in acetic acid/formal saline [AFS; $4 \%$ formaldehyde in $10 \%$ acetic acid and $0.85 \%$ sodium chloride $(\mathrm{NaCl})]$. After approximately two months of demineralization, the tissues were embedded in paraffin, sectioned ( $7 \mu \mathrm{m}$ in thickness), and placed on slides precoated with TES (3-aminopropyltriethoxysilane, Sigma Chemical, St. Louis, MO).

\section{Immunohistochemical techniques}

Antibodies: BSP - Two antibodies were tested initially: rabbit 


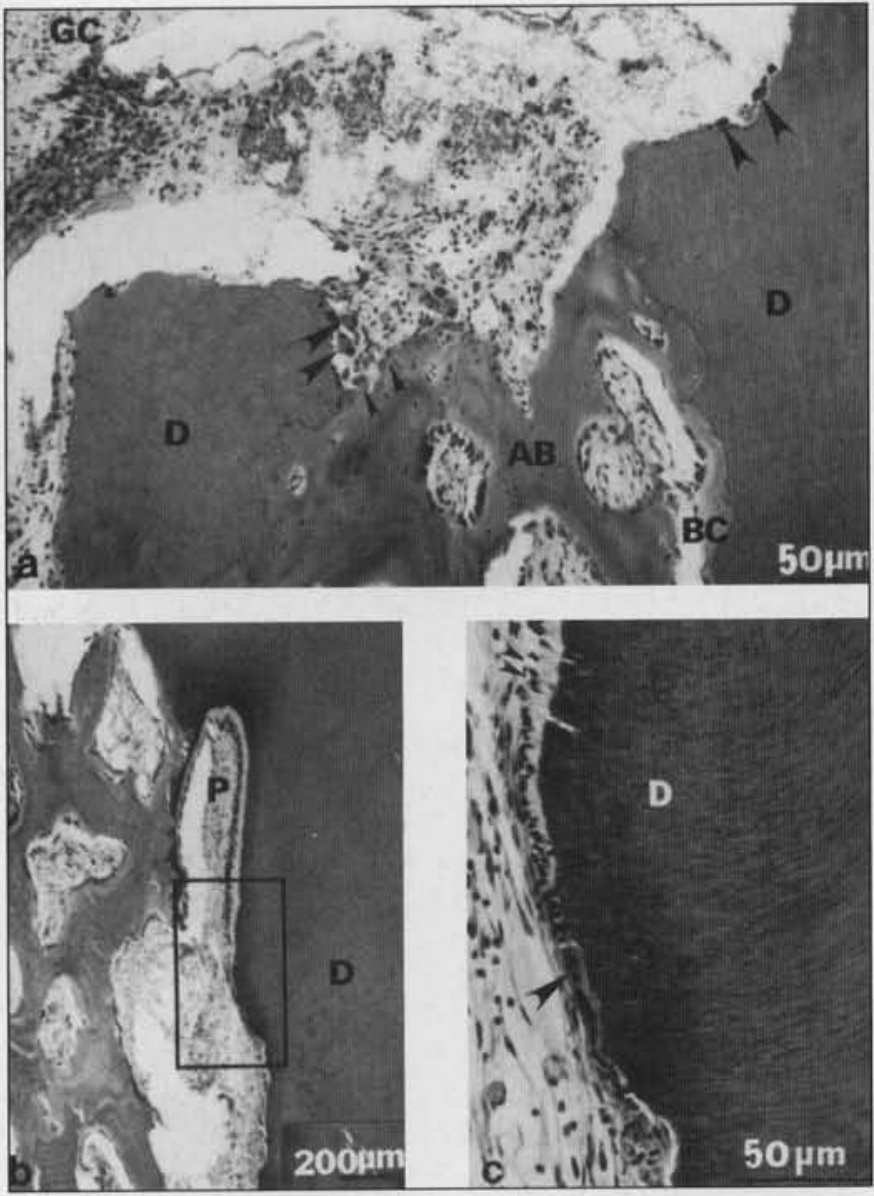

Figure 2. Histology of cat 'neck' lesion. (a) Photomicrographs showing extensive areas of tooth and bone resorption associated with odontoclasts (large arrows) and osteoclasts (small arrows), respectively, and with incomplete repair by bone/cementum-like tissue (BC). (b) Exposure of pulpal tissue (P) to other periodontal tissues as a consequence of extensive tooth resorption. (c) Higher magnification of a square in (b). Odontoblasts (Od) demonstrate a degenerative morphology, including increased vacuoles (small arrows) and loss of cell polarity (large arrow). Abbreviations: GC, gingival connective tissue; GT, granulation tissue; D, dentin; $A B$, alveolar bone. Hematoxylin-eosin staining.

antisera raised against human BSP (LF-6) and bovine BSP (BSP-II), both gifts from Dr. Larry Fisher at NIDR/NIH (1992). Both antibodies localized specifically to areas of mineralization in tissues obtained from cats, with a slightly stronger response achieved with LF-6, and therefore results presented are from studies where LF- 6 was used.

OPN-Two antibodies were tested initially: rabbit antisera raised against human milk OPN [a gift from Dr. Donald R. Senger (Senger et al., 1989), Beth Israel Hospital and Harvard Medical School] and rabbit antisera raised against human bone OPN [gift from Dr. Larry Fisher (1992)]. Human bone OPN antibody resulted in high non-specific background, and therefore results with OPN milk antibody are reported in this study.

$\alpha_{v} \beta_{3}-$ Rabbit antisera prepared from injection of purified human placenta, $\alpha_{v} \beta_{3}$ (heterodimer), was used [a gift from W. Scott Argraves, American Red Cross (Suzuki et al., 1986)].

[To confirm that the BSP and OPN antibodies cross-reacted with cat tissues, we used slot-blot analysis to test a crude protein extract of cat bone (guanidine-EDTA extract) for response to these antibodies. All antibodies used in this study reacted positively in a dose-response fashion (data not shown)].

The method used to localize antigens immunologically was similar to the one described by MacNeil et al. (1994). Xylene was used to remove paraffin, followed by descending series of ethanol concentrations to rehydrate sections. Next, samples were pre-treated with $1 \mathrm{mg} / \mathrm{mL}$ hyaluronidase in $0.1 \mathrm{M}$ sodium acetate buffer ( $\mathrm{pH} 5.5$ ) containing $0.15 \mathrm{M} \mathrm{NaCl}$ for $45 \mathrm{~min}$ at $24^{\circ} \mathrm{C}$. Incubation with $10 \%$ pre-immune goat serum for $10 \mathrm{~min}$ at room temperature blocked non-specific binding. Sections were thoroughly rinsed in PBS with $0.1 \%$ normal goat serum following each incubation step, and all procedures were performed in a humidified chamber. Experimental sections were incubated with primary antibodies diluted 1:50 with Dulbecco's modified Eagle medium (Gibco-BRL, Grand Island, NY) plus $5 \%$ calf serum for $60 \mathrm{~min}$ at room temperature. Control sections were treated in the same manner, but pre-immune rabbit serum was substituted for the primary antibody. Next, sections were treated with affinity-purified goat anti-rabbit IgG conjugated with amino-hexanoyl biotin and then streptavidin conjugated with alkaline phosphatase for $10 \mathrm{~min}$ at room temperature. The enzyme was revealed by the addition of levamisole (an endogenous alkaline phosphatase inhibitor at $50 \mu \mathrm{L} / \mathrm{mL}$ ) and a substrate-chromogen for $15 \mathrm{~min}$ at room temperature. All reagents were provided in the Histostain-SAP kit purchased from Zymed Labs (San Francisco, CA). Tissue response to each antibody was evaluated in at least three separate samples.

\section{In situ hybridization techniques}

Probe preparations. The cDNA probe for bovine type I collagen, $\alpha 1$ (I), was used (a gift from Drs. Marion Young and Larry Fisher, NIDR/NIH). The probe was either linearized with $\mathrm{Xba} I$ and transcribed with T7 RNA polymerase (sense) or linearized with $\mathrm{Xho} I$ and transcribed with T3 RNA polymerase (antisense). The probes were then labeled with $\alpha^{35}$ S-UTP (Amersham, Arlington Heights, IL) by the Riboprobe ${ }^{\circledR}$ Gemini System (Promega Biotec, Madison, WI). Free isotope was separated by NucTrap Push Columns (Stratagene, La Jolla, CA). DNAse was added after labeling to yield a concentration of 1 unit/ $\mu \mathrm{g}$ of DNA. The solution was incubated for $15 \mathrm{~min}$ at $37^{\circ} \mathrm{C}$ with probe extract and an equal volume of phenol/chloroform/isoamyl alcohol (Promega Biotec, Madison, WI). Transcription products were precipitated with $3 \mathrm{M}$ sodium acetate, $\mathrm{pH} 6.0$, and $95 \%$ ethanol at $-70^{\circ} \mathrm{C}$ overnight. After centrifugation at $4^{\circ} \mathrm{C}$ for $15 \mathrm{~min}$, the precipitate was dissolved in hydrolysis solution $(40 \mathrm{mM}$ sodium bicarbonate $/ 60 \mathrm{mM}$ sodium carbonate) and incubated at $60^{\circ} \mathrm{C}$ so that the probe would be reduced to an average size of 150 to $300 \mathrm{bp}$. Size was confirmed by formaldehyde-agarose gel electrophoresis.

In situ hybridization. Sections were deparaffinized and then digested with $10 \mu \mathrm{g} / \mathrm{mL}$ proteinase $\mathrm{K}$ (BoehringerMannheim Biochemica, Mannheim, Germany) in PBS for 30 


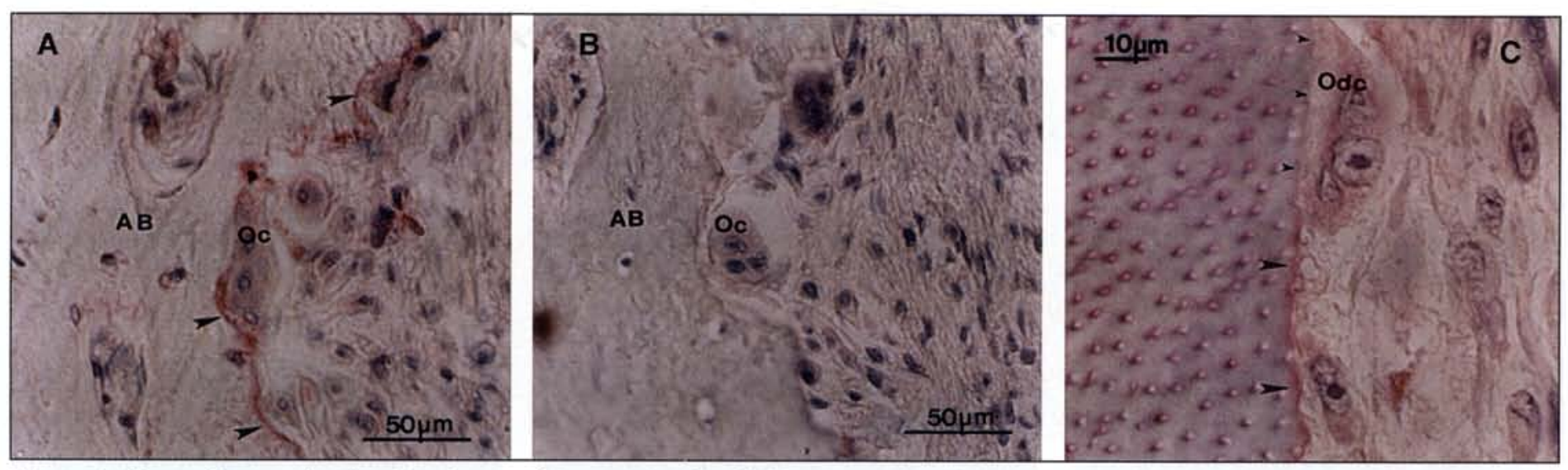

Figure 3. Photomicrographs showing immunohistostaining for OPN at resorption fronts populated by osteoclasts (Oc) and odonoclasts (Odc). (a) Positive reaction for OPN at a bone/soft-tissue interface (arrows). (b) Pre-immune serum control. (c) Positive reaction for OPN at a dentin/soft-tissue interface (arrows) and dentinal tubules. Note lack of a positive reaction at resorption sites facing attached odontoclasts (small arrows, Fig. 3c). Abbreviations: AB, alveolar bone; D, dentin. Counterstaining by hematoxylin.

$\min$ at $37^{\circ} \mathrm{C}$. Sections were then rinsed with sterile water and $0.1 \mathrm{M}$ triethanolamine (TEA), $\mathrm{pH} 8.0$, following which they were acetylated in $0.25 \%$ acetic anhydride in $0.1 \mathrm{M}$ TEA, pH 8.0. Next, the sections were washed in $2 x$ SSC (sodium saline citrate), dehydrated in ascending concentrations of fresh ethanol, and air-dried. The hybridization mixture consisted of $50 \%$ formamide, $0.3 \mathrm{M}$ $\mathrm{NaCl}, 10 \mathrm{mM}$ Tris $\mathrm{HCl}, \mathrm{pH}$ 8.0, 1 mM EDTA, 1x Denhardt's solution, $500 \mu \mathrm{g} / \mathrm{mL}$ of tRNA, $10 \mathrm{mM}$ DTT (dithiothreitol), $10 \%$ dextran sulfate, $100 \mu \mathrm{g} / \mathrm{mL}$ of sperm DNA, and $10^{6}$ cpm of probe $/ 100 \mu \mathrm{L}$. The samples were hybridized overnight at $50^{\circ} \mathrm{C}$ in a humid atmosphere followed by two five-minute rinses with $4 \times$ SSC. After being rinsed, sections were treated for $1 \mathrm{hr}$ at $37^{\circ} \mathrm{C}$ with $50 \mu \mathrm{g} / \mathrm{mL}$ of RNase in 10 $\mathrm{mM}$ Tris $\mathrm{HCl}, \mathrm{pH} 8.0,1 \mathrm{M}$ EDTA, and $500 \mathrm{mM} \mathrm{NaCl}$. Slides were then washed sequentially with $1 \mathrm{mM}$ DTT in $2 \mathrm{x}$ SSC, $1 \mathrm{x} \mathrm{SSC}$, and $0.5 \mathrm{x}$ at room temperature, rinsed with $1 \mathrm{mM}$ DTT in $0.1 \times \mathrm{SSC}$ at $60^{\circ} \mathrm{C}$ for $30 \mathrm{~min}$, dehydrated in ethanol, and air-dried. We exposed slides overnight to x-ray film (Hyperfilm ${ }^{\mathrm{TM}}-\beta$ max, Amersham, Arlington Heights, IL) to demonstrate general hybridization patterns and to determine proper exposure time. Slides for autoradiography were dipped in a 1:1 dilution of Kodak NTB-2 emulsion, airdried, and exposed for $3 \mathrm{wks}$ at $4^{\circ} \mathrm{C}$ in the presence of desiccant. Exposed slides were developed in Kodak D-19 developer for $3 \mathrm{~min}$ at $15^{\circ} \mathrm{C}$, stopped in water, fixed in Kodak fixer, and washed in running tap water. Sections were counterstained with hematoxylin and eosin, dehydrated in ethanol, cleared in xylene, and mounted in Permount ${ }^{\circledR}$ (Fisher Scientific, Fair Lawn, NJ). Hybridization signal was demonstrated by bright- and dark-field microscopy (Olympus BH-2, Japan).

\section{Results}

\section{Immunohistochemical findings}

The kistology of cat 'neck' lesions has been reported (Reichart et al., 1984; Okuda and Harvey, 1992a). Fig. 2 demonstrates the characteristics of lesions examined in this study and confirms that they are similar to other cat 'neck' lesions described in the literature. Lesions were characterized by extensive areas of root dentin resorption and by incomplete repair. Morphologically, repair tissue was bone/cementumlike (BC) in appearance (Fig. 2a). Lesions were populated by odontoclasts and osteoclasts (arrowheads, Fig. 2a), which are named for their apparent resorbing activity on dentin or bone, respectively. In some samples, resorption of root dentin was extensive, resulting in soft-tissue continuity between pulpal tissues and periodontal tissues. In such situations, odontoblasts (Od) lining the inner wall of pulp had a degenerative morphology, demonstrated by increased vacuoles and loss of cell polarity (Figs. 2b, 2c).

Resorption fronts populated extensively by odontoclasts and osteoclasts reacted strongly with OPN antibody (Fig. 3). Cells exhibited faint staining for OPN relative to control cells (Figs. 3a, 3c vs. 3b). However, there were some areas which did not react. Typically, these were sites intimate to attached odontoclasts/osteoclasts-interfaces between attached 'clastic' cells and intact bone or dental tissues (Fig. $3 c$, small arrowhead). Positive reaction to OPN antibody was also observed in reversal lines (cemental lines), thin layers where bone or cementum tissues were newly formed on resorbed dentin (Fig. 4a). Reversal lines which reacted with OPN antibody were continuous with resorption fronts, i.e., small arrowheads (Fig. 4a). Positive staining for OPN was also noted within the odontoclasts (Fig. 4a) and dental tubules (Fig. 3c). In addition, cells embedded within bonecementum (BC) (Fig. 4a) as well as osteocytes associated with alveolar bone (AB) (Fig. 3a) stained weakly for OPN. Reversal lines also reacted with BSP antibody (Fig. 4b). Unlike OPN, resorption fronts did not react with BSP (Fig. $4 \mathrm{~b}$, asterisk). This finding was noted in specimens taken from six different tissue samples. Pulpal tissues did not stain with either OPN or BSP antibodies (data not shown).

Intense staining with $\alpha_{\mathrm{v}} \beta_{3}$ integrin antibody was found on the surfaces of odontoclasts and osteoclasts in areas of resorption. Faint staining was noted within the dentinal tubules (Fig. 5a, arrows). This finding was reproduced in three different samples. 


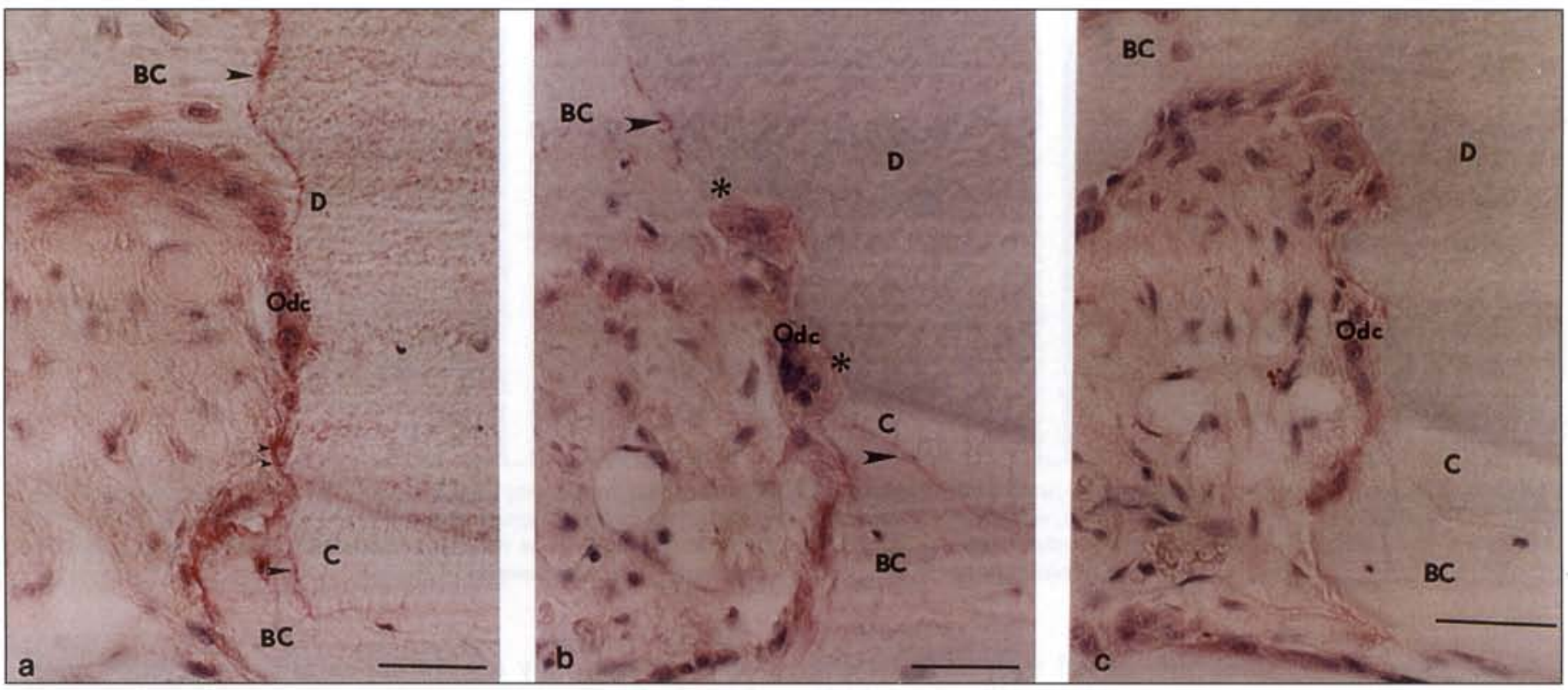

Figure 4. Localization of OPN and BSP at reversal lines and resorption fronts. (a) Photomicrograph showing positive immunohistostaining for OPN at resorption fronts (small arrow) and reversal lines (large arrows). (b) Immunohistostaining for BSP showing positive reaction at reversal lines (arrows). No positive reaction was noted at resorption fronts (*). (c) Pre-immune control. Abbreviations: C, cementum; D, dentin; BC, bone/cementum-like tissue; Odc, odontoclast. Bar $=50 \mu \mathrm{m}$. Counterstaining by hematoxylin. Results shown were taken from one tissue sample.

\section{In situ hybridization findings}

Significantly, type I collagen mRNA was not expressed in odontoblasts (Od) lining the inner wall of pulp exposed as a consequence of resorption (Figs. 6a, 6b, 6c). However, 'osteoblast-like' cells involved in repair of hard tissues demonstrated strong type I collagen expression at the RNA level (Figs. 6a, 6c).

\section{Discussion}

Reported cases of cat 'neck' lesions have increased, but the cause of these lesions and the reason for an increase in lesion numbers have not been established. The studies described here focused on the pathology of this 'disease' at the cellular and molecular levels. Histological results from this study confirm that extensive damage occurs by resorption of both coronal and apical dentin. Advanced lesions extended into the pulp, resulting in degeneration of odontoblasts. Attempts at repair, where dentin had been resorbed, were observed frequently. Reichart et al. (1984) called this newly formed tissue "reparative cementum" or "osteodentin-like material". In contrast, Okuda and Harvey (1992a) suggested that this reparative tissue was significantly different from dentin: Reparative tissue did not contain dentinal tubules, cells involved in repair did not appear to be derived from pulpal tissue, and the histologic appearance of repaired tissue resembled that of bone. Their rationale for suggesting that it was bone-like rather than cementum-like was based on stain density, the presence of marrow-like soft tissue, and lamellar patterning. Results reported here support the concept that the reparative tissue is bone- or cementum-like rather than dentinal. However, a distinction between bone or cementum was not possible. Our conclusion was based on the histologic appearance and expression of type I collagen. Type I collagen mRNA was not expressed strongly by odontoblasts lining the pulp wall. In contrast, type I collagen mRNA was expressed by cells lining the endosteal surface of bone, suggesting that newly formed mineralized tissue was initiated, in part, by osteoblasts from surrounding alveolar bone.

As an initial attempt to understand the mechanisms and factors promoting osteoclast activity, we elected to determine whether OPN, an adhesion molecule that has been inplicated as having a role in promoting osteoclast activity (for review, see Denhardt and Guo, 1993), was localized to regions associated with resorptive activities in tissues obtained from cats with 'neck' lesions. In addition, we determined whether $\alpha_{v} \beta_{3}$, an integrin found in high concentrations on the cell surfaces of osteoclasts, could be identified in resorptive cells in tissue samples from these same lesions. Importantly, since one of the ligands associated with $\alpha_{v} \beta_{3}$ is OPN, we were able to determine, by using serial sections, the association of $\alpha_{v} \beta_{3}$ with OPN. Furthermore, using serial sections from the same lesion, we also examined whether BSP was associated with resorptive and/or reparative processes in these lesions. BSP, a mineralized-tissue-specific protein, has also been identified as a ligand for $\alpha_{v} \beta_{3}$; thus, differences/similarities in the localization of these three proteins would provide insight into the possible mechanisms regulating osteoclast/odontoclast and osteoblast activity during destruction and repair, respectively. As discussed below, the specific regions to which these molecules were localized have allowed us to propose several theories as to the factors/mechanisms controlling these aggressive lesions, resulting in a promising new direction for our studies to confirm our suggested hypotheses. OPN and BSP were 


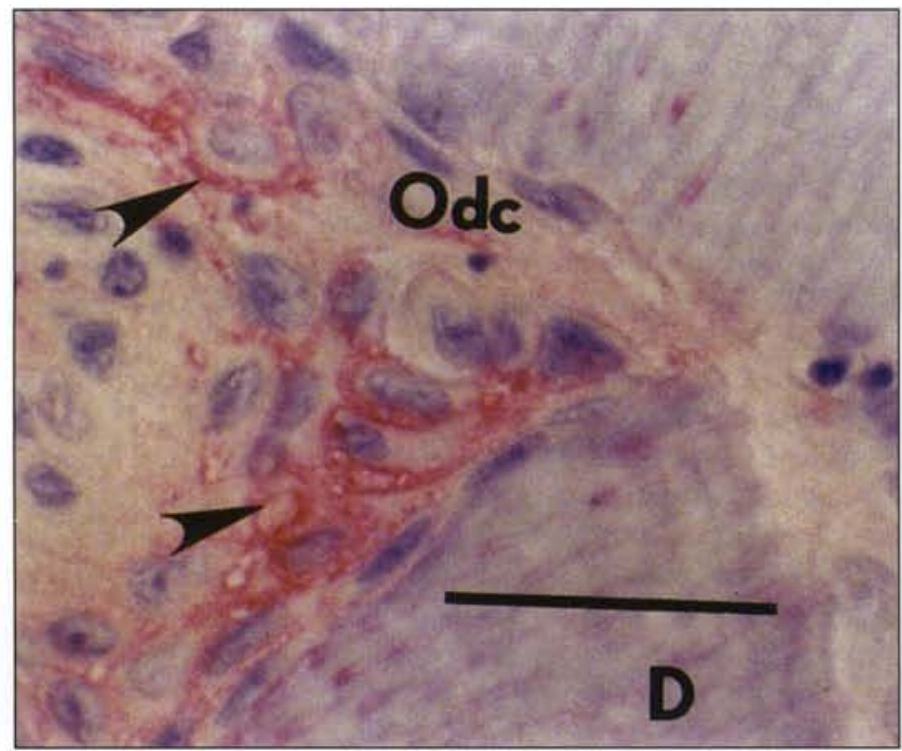

Figure 5. Localization of $\alpha_{v} \beta_{3}$ at resorption fronts. Photomicrograph of immunohistostaining for $\alpha_{\mathrm{v}} \beta_{3}$ showing positive reaction by odontoclasts (Odc) at resorption fronts (arrows). Bar $=50 \mu \mathrm{m}$. D, dentin. Counterstaining by hematoxylin. Results shown were taken from the same tissue sample as shown in Fig. 4.

localized to reversal lines, e.g., sites which separate reparative tissue from intact dentin. Localization of OPN and BSP to mineral/mineral and mineral/soft tissue interfaces during development and in mature tissues has been reported previously (Chen et al., 1993; McKee and Nanci, 1996). Here, we demonstrated that OPN and BSP accumulate at reversal lines during repair. Reversal lines may indicate transitions between resorption and formation for mineralized tissues. In addition, there is some evidence that specific growth factors, e.g., transforming growth factors $\beta$ (TGF- $\beta$ s) and/or bone morphogenetic proteins (BMPs), implicated in the regulation of osteoblast-osteoclast homeostasis, accumulate at reversal lines (Oguro and Ozawa, 1988; Kingsley, 1994). Thus, several molecules localized to reversal lines may play important roles in maintaining mineralized tissue homeostasis.

A strong relationship between OPN and osteoclasts was noted. Additionally, $\alpha_{v} \beta_{3}$ was prominent on 'clastic' cell surfaces in areas of resorption and was closely associated with surfaces where OPN reacted strongly (Fig. 5, serial sections), suggesting a functional link between $\alpha_{\mathrm{v}} \beta_{3}$ and OPN in cat 'neck' lesions. This possibility is supported by other studies which indicate that OPN interacts with the $\alpha_{v} \beta_{3}$ receptor on osteoclasts and promotes osteoclast binding to resorptive sites (Reinholt et al., 1990). However, the exact interaction between $\alpha_{\mathrm{v}} \beta_{3}$ and OPN on such cells needs to be clarified, especially since many other adhesion molecules are linked with $\alpha_{\mathrm{v}} \beta_{3}$ on cell surfaces (Ross et al., 1993), with reportedly different cell signals depending on the associated ligand (for review, see Denhardt and Guo, 1993). Furthermore, while consensus exists that an OPN$\alpha_{\mathrm{v}} \beta_{3}$ reaction is important for osteoclast attachment to bone (Ross et al., 1993), it has not yet been established whether these two molecules co-localize to specific areas on the osteoclast surface (Lakkakorpi et al., 1991). Lakkakorpi et al. (1991) agree with other researchers in stating that both $\alpha_{\mathrm{v}}$
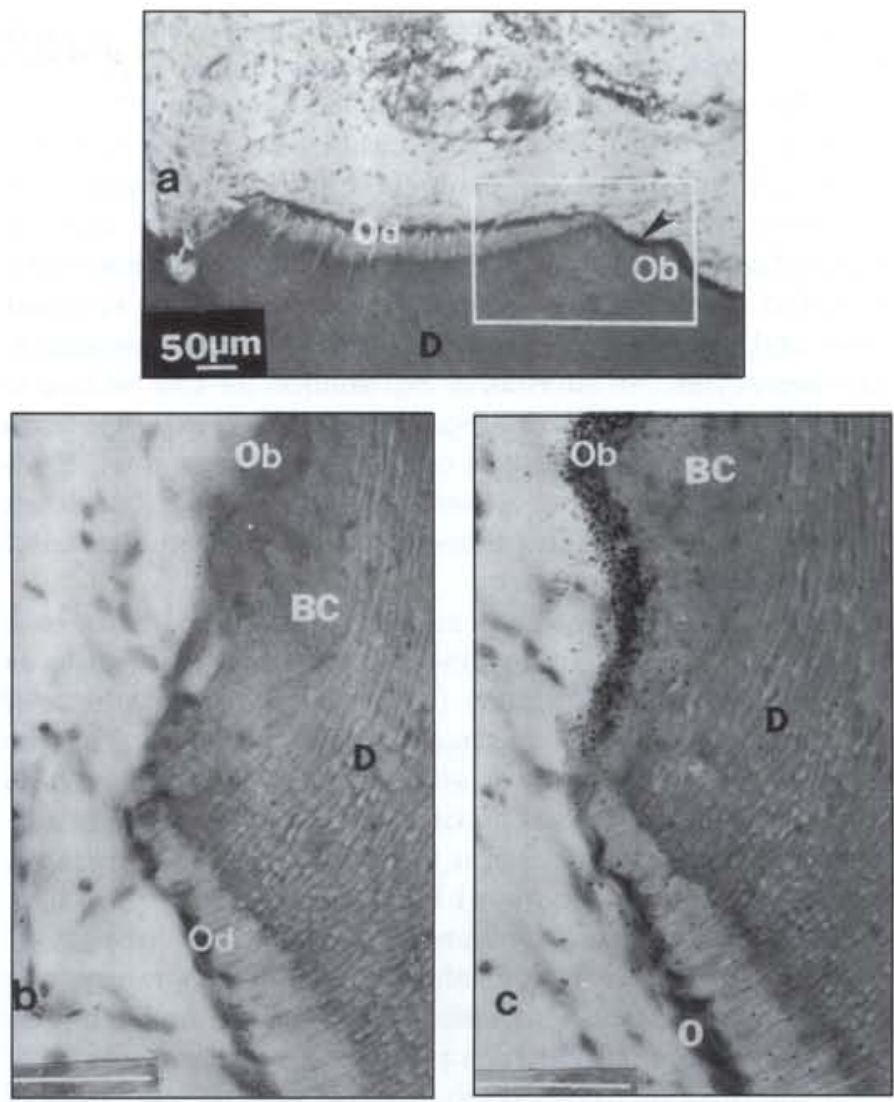

Figure 6. In situ hybridization for type I collagen mRNA. (a) Brightfield image of antisense probe indicating positive expression for type 1 collagen by osteoblasts $(\mathrm{Ob})$, with absence of expression by odontoblasts (Od). (b) Sense probe. (c) Antisense probe; higher magnification of white square outlined in (a). Note intense expression for type I collagen by osteoblasts (Ob), black grains in bright-field, with lack of expression by odontoblasts (Od). Abbreviations: D, dentin; $\mathrm{BC}$, bone/cementum-like tissue; Od, odontoblasts; $\mathrm{Ob}$, osteoblasts. Counterstaining by hematoxylin and eosin.

and $\beta_{3}$ subunits are important for osteoclast activity; however, they failed to demonstrate the localization of $\alpha_{\mathrm{v}} \beta_{3}$ to the sealing zone. This led them to conclude that $\alpha_{\mathrm{v}} \beta_{3}$ may not be critical for final sealing zone attachment of the osteoclasts to bone surfaces, as required for creation of an isolated local micro-environment where resorption activity can occur. At the light microscopic level, we were not able to determine if $\alpha_{\mathrm{v}} \beta_{3}$ was associated with sealing zones on osteoclasts. However, OPN was localized to the regions of osteoclasts demonstrating $\alpha_{v} \beta_{3}$ receptors, i.e., resorption sites, whereas BSP was not identified in these regions. In spite of this association, we noted that OPN did not localize to sites where "clastic" cells appeared to be sitting directly on bone. Thus, it is possible that OPN, through one of its target receptors, e.g., $\alpha_{v} \beta_{3}$, triggers cell signals as yet to be identified, resulting in osteoclast adhesion and subsequent activation. Evidence from other studies supports our conclusion that OPN may have a critical role in the resorptive phase of bone remodeling, while BSP may play a more significant role in the initiation of mineralization (for review, see Bianco et al., 1991; Sodek et al., 1992; Denhardt and Guo, 1993). However, other factors must be considered, 
especially since other studies have identified weak staining for BSP in osteoclasts from human bones (Bianco et al., 1991) and the synthesis of BSP by osteoclast-like cells (FLG 29.1; Masi et al., 1995). Thus, BSP cannot be ruled out as a molecule important for osteoclast activity. Indeed, it is possible that there was a loss of protein during decalcification and/or that the plane of sectioning may have resulted in variability in staining for proteins at reversal lines and resorption fronts, and in odontoclasts, osteoclasts, and osteocytes. An alternative explanation for this finding is that cells are at different stages of functional activity. Such variation in OPN staining in osteoclasts (Maeda et al., 1994) as well as staining for other proteins in cells has been reported previously, and these results have been attributed to differences in cell activity.

These results provide several possibilities as to a function(s) of OPN in aggressive osteoclast resorption as observed in cat 'neck' lesions: (1) Increased concentrations of OPN produced locally in response to inflammatory agents promote migration and/or attachment of "clastic" cells to these areas; (2) increased concentrations of OPN locally result in up-regulation of $\alpha_{v} \beta_{3}$ cell-surface receptors on osteoclasts with subsequent local increase in osteoclasts; and/or (3) increased concentrations of OPN, produced locally, serve a protective role, i.e., inhibit programed cell death in osteoclasts. This latter hypothesis is supported by several findings. Tumor cells producing high levels of OPN have the capacity to defend themselves against mediators of cell death. This has been attributed to the ability of OPN to effect expression of specific genes/proteins that are noxious to cells, such as nitrous oxide synthetase, and to inhibit killing of tumor cells by activated macrophages and endothelial cells (Denhardt and Chambers, 1994). Our studies to date, demonstrating that OPN localizes to areas associated with resorptive activity, have prompted us to propose that OPN protects osteoclasts from cell death, resulting in "uncoupling" of osteoblast-osteoclast homeostasis in favor of osteoclast resorptive activity. Future studies have been planned to address this hypothesis.

\section{Acknowledgments}

The authors thank Jessica Madow and Mary Schmidt for assistance in the preparation of the manuscript. This work was supported by Nestec Ltd. (Friskies Research).

\section{References}

Albelda SM, Buck CA (1990). Integrins and other cell adhesion molecules. FASEB J 4:2868-2880.

Bianco P, Fisher LW, Young MF, Termine JD, Robey PG (1991). Expression of bone sialoprotein (BSP) in developing human tissues. Calcif Tissue Int 49:421-426.

Boskey AL, Maresca M, Ullrich W, Doty SB, Butler WT, Prince CW (1993). Osteopontin-hydroxyapatite interactions in vitro: inhibition of hydroxyapatite formation and growth in a gelatin-gel. Bone Miner 22:147-159.

Chen J, McCulloch C, Sodek J (1993). Bone sialoprotein in developing porcine dental tissues: cellular expression and comparison of tissue localization with osteopontin and osteonectin. Arch Oral Biol 38:241-249.

Coles S (1990). The prevalence of buccal cervical root resorptions in Australian cats. J Vet Dent 7:14-16.

Denhardt DT, Chambers AF (1994). Overcoming obstacles to metastasis-defenses against host defenses: Osteopontin (OPN) as a shield against attack by cytotoxic host cells. I Cell Biochem 56:48-51.

Denhardt DT, Guo X (1993). Osteopontin: a protein with diverse functions. FASEB J 7:1475-1482.

Fisher LW (1992). Structure/function studies of the sialoglycoproteins and proteoglycans of bone: It is still the early days. In: Chemistry and biology of mineralized tissues. Slavkin H, Price P, editors. Amsterdam-New York: Excerpta Medica, pp. 177-187.

Harvey CE (1992). Epidemiology of periodontal conditions in dog and cats. Proceedings of the Sixth Annual Veterinary Dental Forum, the American Veterinary Dental College and the Academy of Veterinary Dentistry, Nov 13-15, 1992, Las Vegas, Nevada. Nabisco Foods Company, pp. 45-46.

Helfrich MH, Nesbitt SA, Dorey EL, Horton MA (1992). Rat osteoclasts adhere to a wide range of RGD (Arg-Gly-Asp) peptide-containing proteins, including the bone sialoproteins and fibronectin, via a $\beta 3$ integrin. J Bone Miner Res 7:335-343.

Hunter GK, Goldberg HA (1994). Modulation of crystal formation by bone phosphoproteins: role of glutamic acidrich sequences in the nucleation of hydroxyapatite by bone sialoprotein. Biochem J 302:175-179.

Hunter GK, Kyle CL, Goldberg HA (1994). Modulation of crystal formation by bone phosphoproteins: structural specificity of the osteopontin-mediated inhibition of hydroxyapatite formation. Biochem I 300:723-728.

Kingsley DM (1994). The TGF 13 superfamily: new members, new receptors, and new genetic tests of function in different organisms. Gene Dev 8:133-146.

Lakkakorpi PT, Horton MA, Helfrich MH, Karhukorpi E-K, Vaananen HK (1991). Vitronectin receptor has a role in bone resorption but does not mediate tight sealing zone attachment of osteoclasts to the bone surface. J Cell Biol 115:1179-1186.

MacNeil RL, Sheng N, Strayhorn C, Fisher LW, Somerman MJ (1994). Bone sialoprotein is localized to the root surface during cementogenesis. J Bone Miner Res 9:1597-1606.

Maeda H, Kukita T, Akamine A, Kukita A, Ijima T (1994). Localization of osteopontin in resorption lacunae formed by osteoclast-like cells: a study by a novel monoclonal antibody which recognizes rat osteopontin. Histochem 102:247-254.

Masi L, Brandi ML, Robey PG, Crescioli C, Calvo JC, Bernabei P, et al. (1995). Biosynthesis of bone sialoprotein by a human osteoclast-like cell line (FLG 29.1). J Bone Miner Res 10:187-196.

McKee MD, Nanci A (1996). Osteopontin at mineralized tissue interfaces in bone, teeth and osseointegrated implants: Ultrastructural distribution and implications for mineralized tissue formation, turnover and repair. Microsc Res Technique 33:141-164.

Oguro I, Ozawa H (1988). The histochemical localization of acid phosphatase activity in BMU. J Bone Min Metab 6:44-49. 
Okuda A, Harvey CE (1992a). Etiopathogenesis of feline dental resorptive lesions. Vet Clin North Am Small Anim Pract 22:1385-1404.

Okuda A, Harvey CE (1992b). Immunohistochemical distributions of interleukins as possible stimulators of odontoclastic resorption activity in feline dental resorptive lesions. Proceedings of the Sixth Annual Veterinary Dental Forum, the American Veterinary Dental College and the Academy of Veterinary Dentistry, Nov 13-15, 1992, Las Vegas, Nevada. Nabisco Foods Company, pp. 41-43.

Patarca R, Saavedra RA, Cantor H (1993). Molecular and cellular basis of genetic resistance to bacterial infection: The role of the early T-lymphocyte activation-1/osteopontin gene. Crit Rev Immunol 13:225-246.

Regezi JA, Sciubba JJ (1989). Abnormalities of dental pulp: Internal resorption. In: Oral pathology: Clinical-pathologic correlations. Philadelphia: W.B. Saunders Co., pp. 483-484.

Reichart PA, Durr U-M, Triadan H, Vickendey G (1984). Periodontal disease in the domestic cat. A histopathologic study. J Periodont Res 19:67-75.

Reinholt FP, Hultenby K, Oldberg A, Heinegard D (1990). Osteopontin-a possible anchor of osteoclasts to bone. Proc Natl Acad Sci USA 87:4473-4475.

Ross FP, Chappel J, Alvarez JI, Sander D, Butler WT, FarachCarson MC, et al. (1993). Interactions between the bone matrix proteins osteopontin and bone sialoprotein and the osteoclast integrin $\alpha_{v} \beta_{3}$ potentiate bone resorption. I Biol Chem 268:9901-9907.

Schneck GW, Osborn JW (1976). Neck lesions in the teeth of cats. Vet $\operatorname{Rec}$ 99:100.

Senger DG, Perruzzi CA, Papadopoulos A, Tenen DG (1989). Purification of a human milk protein closely similar to tumor-secreted phosphoproteins and osteopontin. Biochem Biophys Acta 996:43-48.

Shiraga $\mathrm{H}$, Min W, VanDusen WJ, Clayman MD, Miner D, Terrell $\mathrm{CH}$, et al. (1992). Inhibition of calcium oxalate crystal growth in vitro by uropontin: another member of the aspartic acid-rich protein superfamily. Proc Natl Acad Sci USA 89:426-430.

Sodek J, Chen J, Kasugai S, Nagata T, Zhang Q, Mckee MD, et al. (1992). Elucidating the functions of bone sialoprotein and osteopontin in bone formation. In: Chemistry and biology of mineralized tissues. Slavkin $\mathrm{H}$, Price P, editors. Amsterdam-New York: Excerpta Medica, pp. 297-307.

Suzuki S, Argraves WS, Pytela R, Arai H, Krusius T, Pierschbacher MD, et al. (1986). cDNA and amino acid sequences of the cell adhesion protein receptor recognizing vitronectin reveal a transmembrane domain and homologies with other adhesion protein receptors. Proc Natl Acad Sci USA 83:8614-8618. 